\title{
Phi Shape UWB Antenna with Band Notch Characteristics
}

\author{
K. V. Ajetrao \\ Department of Electronics \& Telecommunication Engineering \\ Dr. D. Y. Patil Institute of Technology \\ Pune, Maharashtra, India \\ kiran_ajetrao@rediffmail.com
}

\author{
A. P. Dhande \\ Department of Electronics \& Telecommunication \\ Pune Institute of Computer Technology \\ Pune, Maharashtra, India \\ apdhande@pict.edu
}

\begin{abstract}
In this paper a novel band notch antenna in UWB frequency range is designed using split rings. Split rings are overlapped with designed monopole to give phi shape. The slit gap gives band-notch operation from $5.1 \mathrm{GHz}$ to $6.29 \mathrm{GHz}$ and from $4.94 \mathrm{GHz}$ to $5.91 \mathrm{GHz}$ for SPSSR and SPSCR antennas respectively. Simulated and measured results are in good agreement.
\end{abstract}

Keywords-monopole; split ring resonator; band-notch; UWB antenna; VSWR

\section{INTRODUCTION}

For a wireless communication system, large bandwidth is an important requirement. Although UWB antenna gives large bandwidth of $7.7 \mathrm{GHz}(3.1 \mathrm{GHz}$ to $10.6 \mathrm{GHz})$, it faces many challenges of interference with existing systems in UWB range. To avoid this interference with existing systems like WLAN, HIPPERLAN, WiMAX, C-band satellite communication etc., band notch antennas are nowadays becoming popular and necessary for communication. In this paper a novel band notch antenna is designed by merging a monopole antenna with a square or circular split ring resonator. This proposed antenna shape looks like the Greek letter Phi $(\varphi)$ hence is named as split Phi shape square ring (SPSSR) antenna and split Phi shape circular ring (SPSCR) antenna. Both antennas give single band notch operation in UWB band. Monopole is designed at $3 \mathrm{GHz}$. The parameters for the SPSSR antenna are designed, optimized and applied to the SPSCR antenna. It is found that both antennas give the same response hence the same design can be extended to any other shape as well. In proposed antennas, by varying the split gap of rings, band notch frequency can be tuned to the desired band. The length and width of split ring resonator gives inductance, and the gap between two rings and the slit gap of the rings gives the capacitance. The gap between the rings and the slit gap is optimized to give UWB antenna with notch band characteristics. At slit gap of $1.1 \mathrm{~mm}$ the UWB operation in with band notch at 5.87 and $5.47 \mathrm{GHz}$ is achieved for SPSSR and SPSCR respectively.

Many antennas with band-notch characteristics are reported. Band-notch characteristics are achieved by inserting different slots in the radiating patch [1-3]. In [4, 5] antennas with etching slots shapes such as $\mathrm{H}, \mathrm{M}$, W etc. slots in the ground plane are reported. A band notch antenna by etching a narrowband dual resonance fractal binary tree in the radiation element of the conventional UWB antenna is reported in [6], but the antenna manufacturing and structure are complex. The band-notched characteristics are obtained by adding a stepped impedance resonator (SIR) or a split ring resonator (SRR) on the feed line or cutting slots in the ground plane [7, 8]. A bandnotch antenna is designed by etching a nested CSRR inside the ground plane in [9].

Another technique to obtain band-notch characteristics is by adding the parasitic elements in the form of printed strips placed in the radiating aperture of the planar antenna at the top and bottom layer. They are employed to suppress the radiation at certain frequencies within an ultra-wide frequency band [10, 11]. By inserting the U-shaped parasitic element on the bottom plane of the basic planar monopole antenna [12] or by using a pair of arc shaped parasitic elements around the patch, an excellent notched frequency band for rejecting the WLAN band $(5-6 \mathrm{GHz})$ can be obtained [13]. The electromagnetic coupling of the SRR with the CPW yields the frequency notch [14]. There are many more techniques used to obtain bandnotch operation in UWB range. The proposed antenna is simple to design and implement. By changing the slit gap of the antenna the desired band-notch frequency can be tuned. Additional varactor diode can be implemented with the antenna as a future scope to give variable capacitance and the same antenna can be used to tune different frequency bands. The proposed antenna was carefully fabricated and measured. The return loss, VSWR, and impedance are measured to certify the performance. Results show acceptable discrepancy between simulation and measurement due to the influence of the SMA connector for testing and the indoor measurement environment.

\section{PHI SHAPE UWB ANTENNA WITH BAND NOTCH CHARACTERISTICS}

Initially a monopole antenna at $3 \mathrm{GHz}$ frequency is designed. The height of monopole antenna will be $\lambda / 4$. Heights of monopole antenna and ground plane dimensions are fixed by optimization. Designed square and circular shape split ring resonators are overlapped with monopole to form the proposed phi shape antennas. The proposed SPSSR and SPSCR antennas for band notch applications in UWB range are shown in Figure 1. The length of the outer ring is $38 \mathrm{~mm}$ and the ring width is 
$1.1 \mathrm{~mm}$. Outer and inner rings are separated by $0.7 \mathrm{~mm}$. Both antennas have a split gap of $1.1 \mathrm{~mm}$. Detailed dimensions are shown in Table I. The length of rings with specified width gives the inductance and the spacing between the two rings and their slit gap gives the capacitance. The inductance can be changed by changing the length and width of rings whereas the capacitance by changing the spacing and slit gap of rings. Resonance frequency is a function of inductance and capacitance. Hence the resonance frequency for the square and circular ring is given as in (1) [15]

$$
f_{0}=\frac{1}{2 \pi} \sqrt{\frac{1}{L_{e} C_{e}}}
$$

$\mathrm{Le}$ and $\mathrm{Ce}$ are the equivalent inductance and capacitance values of square and circular split rings.

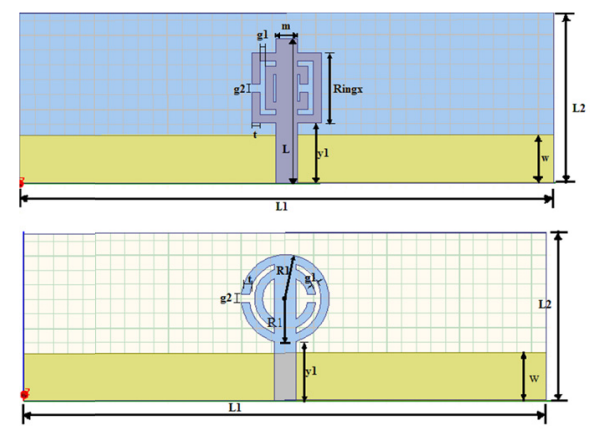

Fig. 1. SPSSR antenna and SPSCR antenna

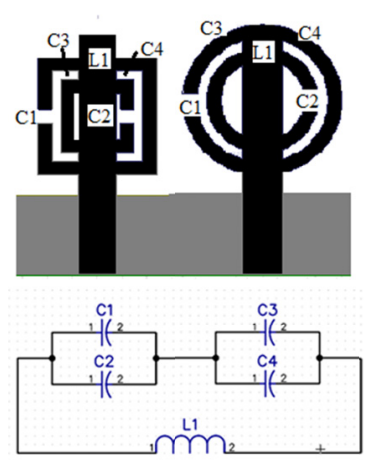

Fig. 2. Empirical antenna equivalent circuit.

From the empirical equivalent circuit diagram shown in Figure 2, L1 is the total equivalent inductance of the circuit, C1 and $\mathrm{C} 2$ are capacitance because of the slit gap in outer and inner rings and $\mathrm{C} 3$ and $\mathrm{C} 4$ are capacitance between the ring and monopole on left half and right half of antenna. Resonance frequency of the proposed antenna is calculated by taking (1) into consideration. The total equivalent capacitance of the circuit is given by (2) [16] as

$$
C_{e}=\frac{\left(C_{1}+C_{3}\right)\left(C_{2}+C_{4}\right)}{\left(C_{1}+C_{3}\right)++\left(C_{2}+C_{4}\right)}
$$

Considering $\mathrm{C}_{1}=\mathrm{C}_{2}=C_{a}$ and $\mathrm{C}_{3}=\mathrm{C}_{4}=C_{g}$, (2) can be written as:

$$
C_{e}=\frac{C_{a}+C_{g}}{2}
$$

Metal thickness of copper is $\mathrm{p}=35 \mu \mathrm{m}$, ring width is $\mathrm{t}$, gap between rings is $\mathrm{g}_{1}$ and $\varepsilon_{0}=8.854187817 \times 10^{-12} \mathrm{~F} / \mathrm{m} . C_{g}$ can be written as

$$
C_{g}=\frac{\varepsilon_{0} t p}{g_{1}}
$$

$C_{a}$ for square rings is given by (5) $[13,16]$ as

$\mathrm{C}_{\mathrm{a}}=\left(4 \mathrm{a}_{\mathrm{avg}}-\mathrm{g}_{1}\right) \mathrm{C}_{\mathrm{p}}$

$C_{a}$ for circular rings is given by (6) [15] as

$C_{a}=\left(\pi r_{a v g}-g_{1}\right) C_{p}$

$a_{a v g}, \pi r_{a v g}$ and $C_{p}$ are calculated as in [13, 15-17].

Equivalent inductance Le calculation for rectangular/circular cross section of wire with finite length $l$ $(\mathrm{mm})$ and thickness of ring $t(\mathrm{~mm})$ is proposed in [18]. The same concept is used to calculate the equivalent inductance $L e$ of SPSSR and SPSCR antenna for band notch applications in UWB range. The equivalent inductance $L e$ for SPSSR antenna is:

$$
L_{e}=0.0002 l\left(2.303 \log _{10} \frac{4 l}{c}-r\right) \mathrm{microH}
$$

where, $\Upsilon$ is the constant for wire loop of square geometry,

$$
l=8 a_{\text {ext }}-g_{1} ; \quad a_{\text {ext }}=\frac{\text { Ringx }}{2} ; \Upsilon=2.853
$$

The equivalent inductance Le for SPSCR antenna is the same as in (7) but with different $(\Upsilon)$ constant for wire loop of circular geometry and:

$$
l=2 \pi r_{\text {ext }}-g_{1} ; \quad r_{\text {ext }}=R_{1} ; \Upsilon=2.451
$$

Using (2)-(9) in (1) gives the ring resonance. The proposed concept in $[13,15-18]$ is used to design the proposed SPSSR and SPSCR antennas for band notch applications in UWB range. Calculated dimensions with some optimization are used to simulate the proposed antenna.

TABLE I. ANTENNA DIMENSIONS

\begin{tabular}{|c|c|c|}
\hline Parameter & $\begin{array}{c}\text { SPSSR antenna } \\
\text { dimensions }\end{array}$ & $\begin{array}{c}\text { SPSCR antenna } \\
\text { dimensions }\end{array}$ \\
\hline L1 & $72 \mathrm{~mm}$ & $72 \mathrm{~mm}$ \\
\hline L2 & $23 \mathrm{~mm}$ & $23 \mathrm{~mm}$ \\
\hline $\mathrm{L}$ & $19.5 \mathrm{~mm}$ & $19.5 \mathrm{~mm}$ \\
\hline $\mathrm{M}$ & $3 \mathrm{~mm}$ & $3 \mathrm{~mm}$ \\
\hline $\mathrm{y} 1$ & $7.9 \mathrm{~mm}$ & 7.9 \\
\hline $\mathrm{W}$ & $6.5 \mathrm{~mm}$ & $6.5 \mathrm{~mm}$ \\
\hline Ring length & $38 \mathrm{~mm}($ ringx=9.5mm $)$ & $38 \mathrm{~mm}(\mathrm{R} 1=6.05 \mathrm{~mm})$ \\
\hline T & $1.1 \mathrm{~mm}$ & $1.1 \mathrm{~mm}$ \\
\hline $\mathrm{g} 1$ & $0.7 \mathrm{~mm}$ & $0.7 \mathrm{~mm}$ \\
\hline $\mathrm{g} 2$ & $1.1 \mathrm{~mm}$ & $1.1 \mathrm{~mm}$ \\
\hline $\mathrm{H}$ & $1.6 \mathrm{~mm}$ & $1.6 \mathrm{~mm}$ \\
\hline
\end{tabular}

\section{RESULTS AND DISCUSSION}

The performance of the proposed antennas is investigated by parametric analysis and the simulated results are validated by measuring the s-parameters and VSWR. The proposed 
antennas are fabricated using an FR4 substrate of $1.6 \mathrm{~mm}$ thickness, 4.4 dielectric constant and 0.02 dielectric loss tangent. The dimensions of both SPSSR and SPSCR antennas are optimised as shown in Table I and the antennas are as shown in Figure 1.

Both antenna designs are simulated with electromagnetic solver based on finite element method. The simulated antennas give good impedence characteristics for both designs. The input impedance is quite close to $50 \Omega$ for both antennas as reflected in Table II. Initial antenna design is done for SPSSR antenna and is applied to SPSCR antenna by using the same optimised dimensions, because of this there may be a slight mismatch in input imedence of SPSCR comapred to SPSSR antenna and results are not exactly matching with each other. To understand the antenna response in better way $S_{11}$ verses frequncy simulated curves are ploted for both designs in Figure 3.

TABLE II. SPSSR AND SPSCR ANTENNA SIMULATED RESULTS

\begin{tabular}{|c|c|c|c|}
\hline Band & Parameters & $\begin{array}{c}\text { SPSSR } \\
\text { antenna }\end{array}$ & $\begin{array}{c}\text { SPSCR } \\
\text { antenna }\end{array}$ \\
\hline \multirow{4}{*}{$\begin{array}{c}\text { UWB } \\
\text { range }\end{array}$} & Frequency Range (GHz) & $2.75-11.4$ & $2.63-11.42$ \\
\cline { 2 - 4 } & S11 in dB & Less than -10dB & $\begin{array}{c}\text { Less than - } \\
10 \mathrm{~dB}\end{array}$ \\
\cline { 2 - 4 } & VSWR & Less than 2 & Less than 2 \\
\cline { 2 - 4 } & Band width in GHz & 8.65 & 8.8 \\
\hline \multirow{4}{*}{$\begin{array}{c}\text { Notched } \\
\text { Band }\end{array}$} & Center frequency (GHz) & $\begin{array}{c}\text { Around } 50 \Omega \text { for } \\
\text { said range }\end{array}$ & $\begin{array}{c}\text { Around } 50 \Omega \\
\text { for said range }\end{array}$ \\
\cline { 2 - 4 } & VSWR & 5.874 & 5.47 \\
\cline { 2 - 4 } & Freuency Band & 6.27 & 4.7 \\
\cline { 2 - 4 } & Notvh-Band BW in $\mathbf{M H z}$ & $1190 \mathrm{MHz}$ & $9.94-5.91$ \\
\cline { 2 - 4 } & Impedance & $140 \Omega$ & $117 \Omega$ \\
\hline
\end{tabular}

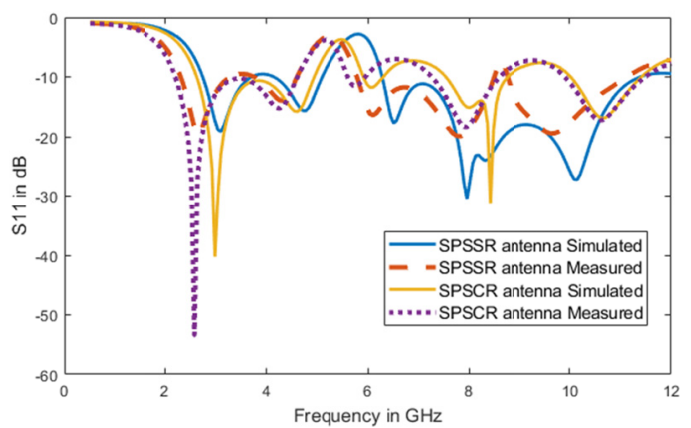

Fig. 3. Simulated and measured $\mathrm{S}_{11}$ SPSSR and SPSCR antenna

From Figures 3 and 4 it is clear that both antennas resonate very close to each other. Simulated and measured results show good agreement with each other for both antennas. Figure 4 shows the simulated and measured VSWR for SPSSR and SPSCR antennas. Figure 5 shows the simulated radiation patterns for the specified bands of SPSSR and SPSCR antennas at $3.4 \mathrm{GHz}$ and $8 . \mathrm{GHz}$ respectively. From the radiation pattern it is clear that both antennas are behaving in similar ways in their respective bands. E-plane pattern resembles with dipole antenna and H-plane pattern is omnidirectional. Radiation pattern gets disturbed at high frequencies. This change in radiation pattern is caused by the change in current distribution at high frequencies.
Figure 6 shows the current distribution for both antennas. From the current distribution pattern at $5.47 \mathrm{GHz}$ and $5.87 \mathrm{GHz}$ for SPSSR and SPSCR in Figure 6(b) and 6(c), it is clear that the current is distributed only in one side and flowing in opposite directions giving band-notch operation.

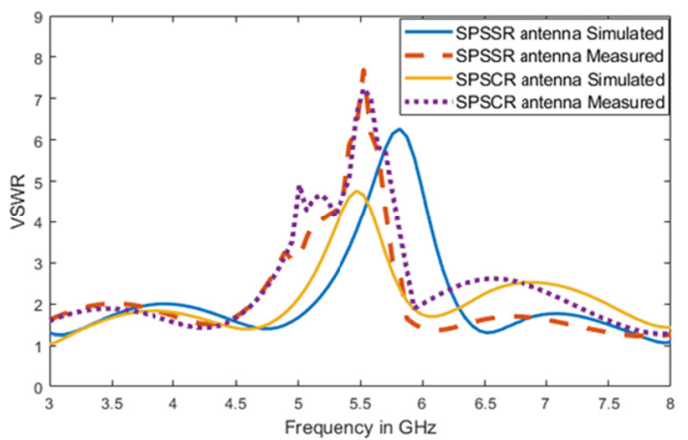

Fig. 4. Simulated and measured VSWR for SPSSR and SPSCR antennas giving band-notch.
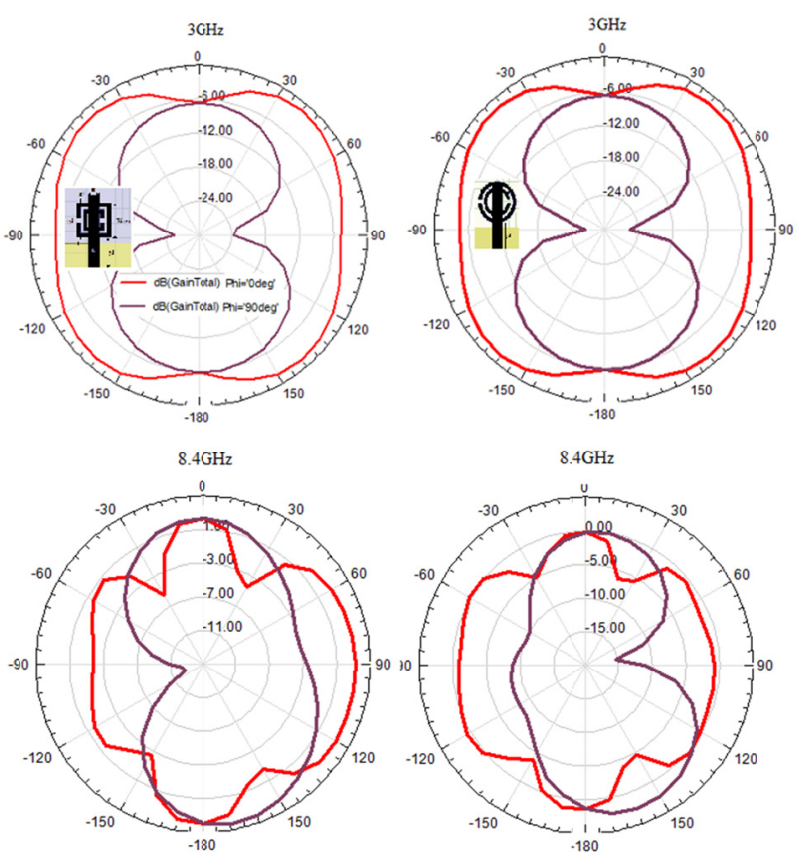

Fig. 5. SPSSR and SPSCR antenna radiation pattern at $3.0 \mathrm{GHz}$ and $8.4 \mathrm{GHz}$

Figure 7 shows the effect of slit gap on band notch frequency. As the slit gap is increased the overall equivalent capacitance decreases and as an effect the notch-band center frequency is increased in both antennas. Hence, desired frequency tuning is possible by changing the slit gap or by connecting varactor diode in between slit gap. The slit gap is optimised to $1.1 \mathrm{~mm}$ which gives band notch operation in WLAN frequency band. Figure 8 shows the gain for both antennas. The gain for both shapes is constant and equal at all frequencies. Figure 9 shows the fabricated antennas. 


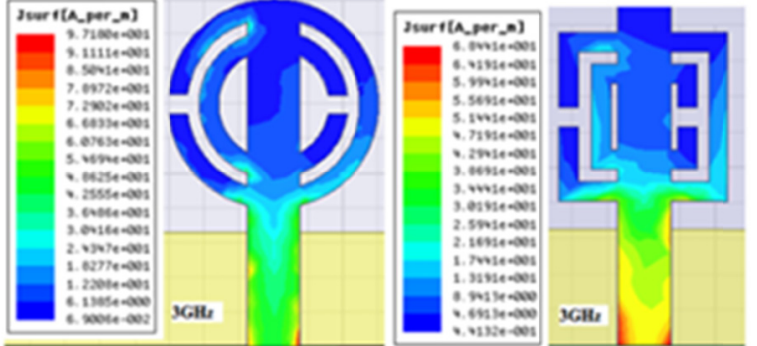

(a)

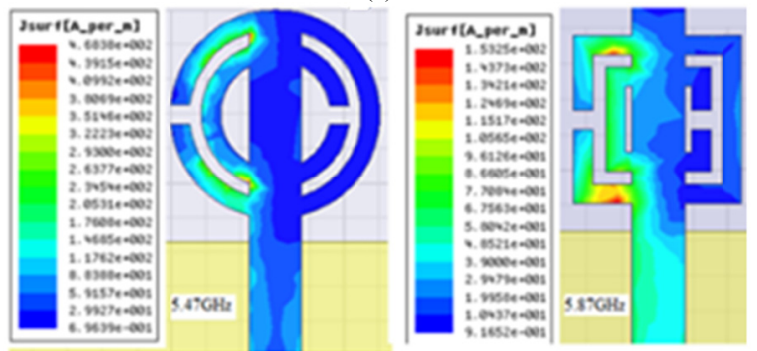

(b)

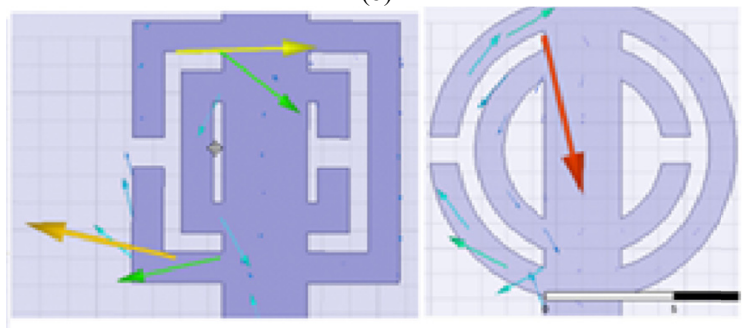

(c)

Fig. 6. Current distribution for SPSSR and SPSCR antennas (a) for radiating patch at frequency of $3 \mathrm{GHz}$ and (b) (c)for notch-band center frequency $5.87 \mathrm{GHz}$ and $5.47 \mathrm{GHz}$ for SPSCR and SPSSR respectively.
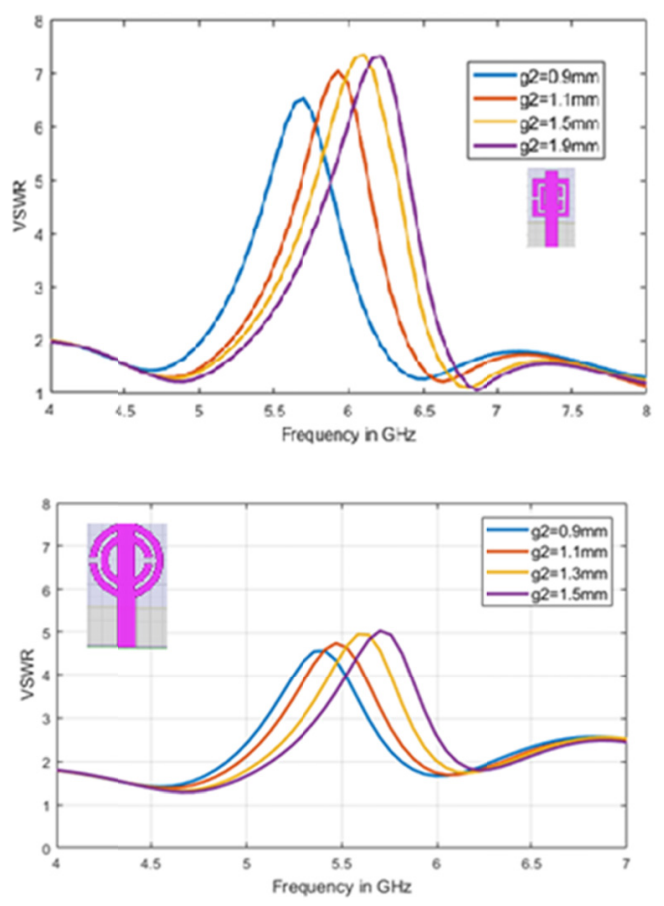

Fig. 7. Effect of slit gap on notch-band frequency.

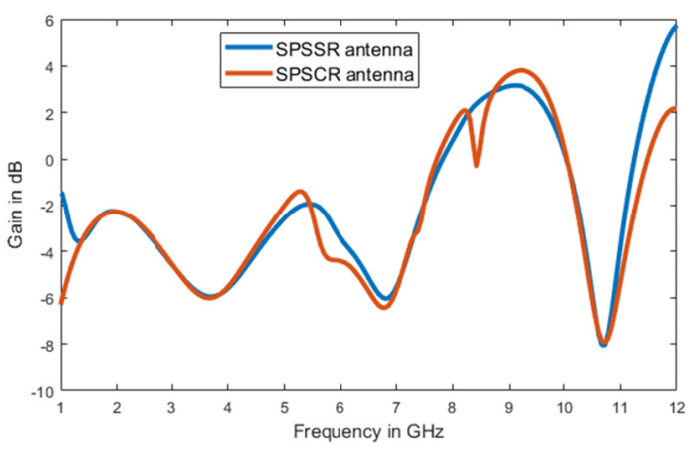

Fig. 8. Gain of SPSSR and SPSCR antenna

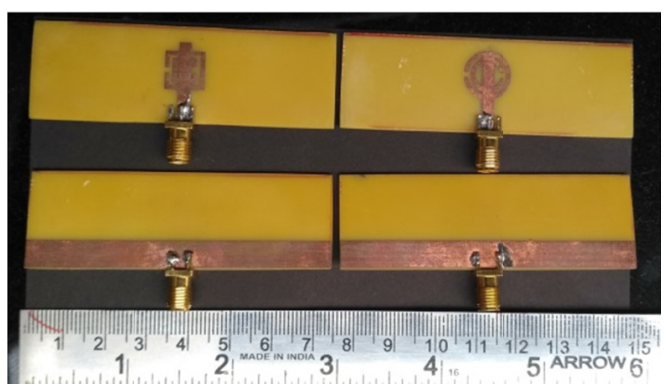

Fig. 9. Fabricated antennas.

\section{CONCLUSIONS}

Applications of UWB antennas find difficulties in avoiding interference with existing systems like WLAN and WiMAX. Band notch antennas are playing an important role in today's wireless communications in UWB range. In this paper, a novel SPSSR antenna is designed and the same design is applied to SPSCR antenna in UWB frequency range. Both designs are giving similar response in terms of $\mathrm{S}_{11}$, VSWR, radiation pattern and gain. It is observed that by increasing the slit gap the equivalent capacitance increases which in turn increases the band-notch center frequency. As future work, a varactor diode can be connected between the slit gap in order to tune the desired frequency. Both antennas are capable of giving band notch at WLAN and WiMAX system frequencies. The notch bands are from $5.1 \mathrm{GHz}$ to $6.28 \mathrm{GHz}$ for SPSSR and $4.94 \mathrm{GHz}$ to $5.91 \mathrm{GHz}$ for SPSCR antenna. Both notch bands are covering the WLAN and WiMAX systems. Interference with WLAN and WiMAX will be avoided by using the proposed antennas. The theoretical design results are verified by simulation for both antennas. Simulated and measured results are in good agreement with each other.

\section{REFERENCES.}

[1] S. Tu, Y. C. Jiao, Y. Song, Z. Zhang, "A Novel Miniature strip-sine fed antenna with Band Notched functions for UWB applications", Progress In Electromagnetics Research Letters, Vol. 10, pp. 29-38, 2009

[2] K. Chung, J. Kim, J. Choi, "Wideband Microstrip-Fed Monopole Antenna Having Frequency Band-Notch Function", IEEE Microwave and Wireless components Letters, Vol. 15, No. 11, pp. 766-768, 2005

[3] M. Naghshvarian-Jahromi ,"Compact UWB Bandnotch Antenna with Transmission Line fed", Progress In Electromagnetics Research B, Vol. 3, pp. 283-293, 2008 
[4] J. Q. Sun, X. M. Zhang, Y. B. Yang, R. Guan, L. Jin "Dual Band Notched ultra-wideband planar Monopole antenna with M and W slots", Progress In Electromagnetics Research Letters, Vol. 19, pp. 1-8, 2010

[5] A. Falahati, M. Naghshvarian-Jahromi, R. M. Edwards "'Dual BandNotch CPW-Ground-Fed UWB Antenna By Fractal Binary Tree Slot", Fifth International Conference on Wireless and Mobile Communications, Cannes, France, August 23-29, 2009

[6] Z. A. Zheng, Q. X. Chu, "Compact CPW-fed UWB Antenna with dual Band Notched Characteristics", Progress In Electromagnetics Research Letters, Vol. 11, pp. 83-91, 2009

[7] Y. Zhang, W. Hong, Z. Q. Kuai, J. Y. Zhou, "A Compact Multiple Bands Notched UWB Antenna by Loading SIR and SRR on the Feed Line", IEEE International Conference on Microwave and Millimeter Wave Technology, Nanjing, China, June, 13, 2008

[8] X. Li, L. Yang, S. X. Gong, Y. J. Yang, "Ultra-Wideband Monopole Antenna with Four-Band-Notched Characteristics", Progress In Electromagnetics Research Letters, Vol. 6, pp. 27-34, 2009

[9] K.-H. Kim, Y.-J. Cho, S.-H. Hwang, S.-O. Park, "Band-notched UWB planar monopole antenna withtwo parasitic patches", Electronics Letters, Vol. 41, No. 14, pp. 783-785, 2005

[10] A. M. Abbosh, M. E. Bialkowski, "Design of UWB Planar BandNotched Antenna Using Parasitic Elements", IEEE Transactions on Antennas and Propagation, Vol. 57, No. 3, pp. 796-799, 2009

[11] B. V. Kadam, L. J. Gudino, C. K. Ramesha, S. Nagaraju, "A Bandnotched Ultra-wideband Compact Planar Monopole Antenna With Ushaped Parasitic Element", Procedia Computer Science, Vol. 93, pp. 101-107, 2016

[12] M. Yazdi, N. Komjani, "A Compact Band-notched UWB Planr Monopole Antenna with Parasitic Elements", Progress In Electromagnetics Research Letters, Vol. 24, pp. 129-138, 2011

[13] J. Y. Siddiqui, C. Saha, Y. M. M. Antar, "Compact SRR Loaded UWB Circular Monopole Antenna With Frequency Notch Characteristics", IEEE Transactions on Antennas and Propagation, Vol. 62, No. 8, pp. 4015-4020, 2014

[14] J. Y. Siddiqui, C. Saha, Y. M. M. Antar, "Compact Dual-SRR-Loaded UWB Monopole Antenna With Dual Frequency and Wideband Notch Characteristics", IEEE Antenna and Wireless Propagation letters Vol. 14, pp. 100-103, 2015

[15] C. Saha, J. Y. Siddiqui, "Versatile CAD Formulation for Estimation of the Resonant Frequency and Magnetic Polarizability of Circular Split Ring Resonators", International Journal of RF and Microwave Computer - Aided Engineering, Vol. 21, No. 4, pp. 432-438, 2011

[16] C. Saha, J. Y. Siddiqui, Y. M. M. Antar, "Square split ring resonator backed coplanar waveguide for filter applications", 2011 XXXth URSI General Assembly and Scientific Symposium, Istanbul, Turkey, August 13-20, IEEE, 2011

[17] I. Bahl, P. Bhartia, Microwave Solid State Circuit Design, 2nd Edition, John Wiley \& Sons, New York, 1998

[18] F. E. Terman, Radio Engineers' Handbook, Mcgraw-Hill, New York, 1943 